\title{
TIPIFICANDO A ECONOMIA DO COMPARTILHAMENTO EA ECONOMIA DO ACESSO
}

\author{
Typifying Sharing Economy and Access Economy
}

\author{
Felipe Gerhard* \\ Jeová Torres Silva Júnior** \\ Samuel Façanha Câmara***
}

\section{RESUMO}

Este estudo visa a criação de uma taxonomia capaz de discriminar os modelos de mercado relacionados aos conceitos de economia do acesso e economia do compartilhamento, buscando-se identificar aspectos e propriedades sui generis a cada uma dessas práticas de mercado. Para tal, uma análise taxonômica foi desenvolvida com base no levantamento dos principais aspectos ontológicos e teóricos relacionados aos dois conceitos. Como categorias de análise foram utilizadas as perspectivas: utilitarista de Mill ([1863] 2005) e anti-utilitarista de Mauss (2003). A construção das classificações e conceitos, ademais, foi guiada por uma abordagem pós-estruturalista com enfoque central nas relações, ao invés da ênfase excessiva em seus elementos constituintes. Como principais resultados destaca-se que a economia do acesso se constitui em dois modelos, predominando a fundamentação utilitária, quais sejam: Modelos baseados na appficação e Modelos disruptivos. Por outro lado, ancorando-se em uma fundamentação anti-utilitária mais ampla, a economia do compartilhamento se divide em Modelos Híbridos e Modelos Colaborativos.

Palavras-chave: Economia do Compartilhamento. Economia do Acesso. Utilitarismo. Anti-utilitarismo. Análise Taxonômica.

\section{ABSTRACT}

This study aims to create a taxonomy capable of discriminating market models related to the concepts of access economy and sharing economy, seeking to identify sui generis aspects and proprieties of these two market practices. For such, a taxonomic analysis was developed based on the survey of the main ontological and theoretical aspects related to both concepts. As analytical categories, utilitarian (MILL, [1863] 2005) and anti-utilitarian (MAUSS, 2003) perspectives were used. Moreover, the construction of classifications and concepts was guided by a poststructuralist approach with central focus on relations, rather than an excessive emphasis on its constituent elements. As main results, we highlight that access economy consists of two models in which the utilitarian foundation predominates, which are: Models based on appfication and Disruptive Models. On the other hand, sharing economy is anchored on a broader anti-utilitarian foundation and is divided into Hybrid Models and Collaborative Models.

Keywords: Sharing Economy. Access Economy. Utilitarianism. Anti-utilitarianism. Taxonomic Analysis.

\footnotetext{
* Doutorando do Programa de Pós-Graduação em Administração da Universidade Estadual do Ceará (PPGA/ UECE) - Fortaleza (CE), Brasil. E-mail: gerhard.sousa@aluno.uece.br. ORCID: 0000-0002-1117-5960

** Doutor em Administração pela Universidade Federal da Bahia (UFBA). Professor do Centro de Ciências Sociais Aplicadas da Universidade Federal do Cariri (CCSA/UFCA). Professor do Programa de Pós-Graduação em Administração da Universidade Estadual do Ceará (PPGA/UECE) - Fortaleza (CE), Brasil. E-mail: jeova.torrres@ ufca.edu.br. ORCID: 0000-0003-0687-1563

*** Doutor em Economia pela Universidade Federal de Pernambuco (UFPE). Professor do Programa de Pós-Graduação em Administração da Universidade Estadual do Ceará (PPGA/UECE) - Fortaleza (CE), Brasil. E-mail: samuel.camara@uece.br. ORCID: 0000-0002-8333-6997
} 


\section{INTRODUÇÃO}

O que 0 ato de presentear, o UberPool, e as bicicletas compartilhadas, populares nas grandes capitais, têm em comum? Todos representam práticas econômicas que, em certa medida, não se adequam de forma plena aos pressupostos do pensamento econômico tradicional; principalmente no que diz respeito ao comportamento dos agentes no mercado. Ao presentear alguém ou ao dividir a corrida de taxi com pessoas jamais vistas, premissas fundamentais para a construção ontológica do homo economicus, como escolhas "racionais", otimização de recursos ou individualismo (EARL, 1990; O'BOYLE, 2007), são violadas. Um novo olhar sobre essa questão, capaz de apreender e explicar tais comportamentos de mercado, até então entendidos sob o viés do exocentrismo, é trazido pela economia do compartilhamento (sharing economy). Os elementos centrais que distinguem tais práticas das relações comerciais tradicionais escapam à ortodoxia inflexiva da concepção clássica de mercado (cf. David Ricardo, [1817] 2001; Adam Smith, [1776] 1996). Por meio de ações como compartilhar e colaborar, relações sociais são reorganizadas e com ela sistemas específicos de produção e circulação de bens e serviços (BELK, 2010, 2014a, 2014b).

Embora apenas recentemente a economia do compartilhamento tenha ganhado proeminência com a Web 2.0, as práticas relacionadas ao conceito precedem - avant le lettre - não somente ao surgimento de perspectivas teóricas que se destinam a compreendê-la, mas às próprias ciências econômicas (FELSON; SPAETH, 1978; FISKE, 1992; CAILLÉ, 2001; LAVILLE, 2003). Diversas formas de desempenhar a economia colaborativa têm se desenvolvido e se transformado em práticas históricas ao longo dos séculos. Nesse contexto, as famílias se destacam por terem criado, em sua essência, um ambiente profícuo à autopreservação, com base nos primeiros hábitos de compartilhamento (KAPLAN, 2001; BELK, 2010; JAEGGI; GURVEN, 2013). Apesar do funcionalismo econômico conceituá-las como uma unidade de capacitação funcional ótima, porquanto transmitiriam ofícios de características tanto masculinas quanto femininas à prole (MARIE, 1978), tais relações são sobrepujadas pelos laços familiares, que transcendem o individualismo dos elos puramente econômicos. Do mesmo modo, apesar de uma marcada divisão social do trabalho, as sociedades pré-letradas geralmente tinham o compartilhamento como prática coletiva sedimentada no cotidiano social (FISKE, 1992; MEAD, 2002; MAUSS, 2003).

Embora o compartilhamento seja destacado como um dos mais importantes elementos norteadores das práticas circunscritas pela sharing economy, ele não é o único. Além do compartilhamento, outros componentes igualmente importantes estão presentes na materialização dessas práticas de mercado, tais como a cooperação, a possibilidade de ganhos não financeiros e a alteridade, representada pelo reconhecimento e maior relevância do outro nas relações econômicas. Esses são os princípios que distinguem as práticas da economia do compartilhamento das práticas econômicas do mercado tradicional (BELK, 2010; 2014b).

A economia do compartilhamento é um conceito que se disseminou rapidamente e tem ganhado grande repercussão, gerando, contudo, certa confusão teórica. Nesse sentido, a perspectiva de uma economia, que possui como base o compartilhamento, é bastante questionada. Críticas à economia do compartilhamento indicam que não se trata realmente 
de compartilhar, mas da generalização do acesso, por um curto período, a um conjunto de itens cuja propriedade é detida por outros consumidores (BARDHI; ECKHARDT, 2012; ECKHARDT; BARDHI, 2015, 2016). O elemento norteador seria, como em qualquer outra troca econômica, a maximização individual dos ganhos; ao invés de um valor social extraordinário. Por essa perspectiva, os axiomas centrais da economia tradicional continuam praticamente inalterados, uma vez que a essência dos elementos que compõem o mercado continua intacta.

Embora deva-se concordar que traços de uma orientação utilitária estejam marcadamente presentes na economia do compartilhamento, ao menos o axioma do egoísmo individualista, suscitado por Thomas Hobbes ([1651] 1999) ainda no século XVII, parece ser questionado. Além dos benefícios econômicos e do júbilo pessoal, as práticas de compartilhar também podem apresentar aspectos tais como a cooperação e a sustentabilidade (BELK, 2014b; HAMARI; SJÖKLINT; UKKONEN, 2015; ERTZ; DURIF; ARCAND, 2016b), fatores que certamente fogem às normas de uma conduta inteiramente individualista.

Mesmo as relações econômicas mais tradicionais são formadas por uma matriz socio-histórica que Ihes atribui um caráter complexo e plural (POLANYI, 2012). Por essa perspectiva, os mercados não deteriam um padrão único de atuação, mas, ao contrário, apresentariam diversos padrões a depender das características e elementos presentes em cada contexto sociocultural. Entretanto, há características que de fato se qualificam como epifenômenos dos mercados capitalistas modernos. Para Simmel ([1903] 2005), uma troca envolvendo compensações monetárias guardaria um caráter peculiar, específico da nossa modernidade. Para ele, dado que o espírito moderno se tornou um espírito de cálculo e exatidão contábil, o dinheiro se tornou capaz de nivelar a todos pelo valor de troca, ao mero quanto. Esse espírito é de certa forma rompido pela economia do compartilhamento, que vem apresentado a cada dia mais exemplos que fogem à lógica puramente contábil apontada por Simmel (2005). Ao passo que conservam um rastro econômico em alguns casos ainda muito forte, as práticas da economia colaborativa se constroem sobre particularidades onto-epistemológicas que dificilmente conseguiriam ser apreendidas pelos axiomas do pensamento econômico tradicional.

Constatando-se as controvérsias suscitadas pela economia colaborativa, expressas tanto em sua dimensão histórica atemporal quanto no questionamento dos pressupostos da economia tradicional, e na sua relação com a economia do acesso, o presente estudo guia-se pelas seguintes perguntas de pesquisa: Quais são as propriedades e características que de fato definem e diferenciam cada um desses conceitos? Até que ponto eles se inter-relacionam? Com base nesses questionamentos, este estudo visa a criação de uma taxonomia capaz de discriminar ao passo que relaciona os conceitos de economia do acesso e economia do compartilhamento. Ademais, serão analisadas as suas características peculiares, buscando-se o levantamento de aspectos e propriedades sui generis a cada uma dessas práticas de mercado. Cumpre destacar que estudos existentes na literatura já buscaram tipificar aspectos específicos da economia do compartilhamento (RIVERA et al., 2017) ou ela como um todo (WAVE, 2014; PERREN; GRAUERHOLZ, 2015; PLEWNIA; GUENTHER, 2018). Contudo, comparações sistemáticas entre as economias do compartilhamento e acesso ainda não foram realizadas. 
Para a construção da proposta taxonômica deste estudo, são destacadas as similaridades e divergências entre as práticas das economias do acesso e compartilhamento. Para tal, utilizando-se como categorias de análise os aspectos teóricos das perspectivas utilitarista e antiutilitarista, as duas economias são seccionadas em quatro modelos econômicos: Modelos baseados em appficação; Modelos disruptivos; Modelos híbridos e; Modelos colaborativos. Ao final, uma taxonomia relacionando os quatros modelos construídos nesta pesquisa é apresentada.

\section{PRÁTICAS DA ECONOMIA DO COMPARTILHAMENTO VSPRÁTICAS DA ECONOMIA DO ACESSO}

Por não haver qualquer consenso sobre o que define uma prática econômica como de compartilhamento, o entendimento do fenômeno pela literatura tem se dado principalmente pela apresentação de protótipos empíricos. Desse modo, ao tratar do tema, os autores geralmente apresentam exemplos de plataformas que se auto-intitulam como representantes da economia do compartilhamento. Na maioria dos casos, são utilizados exemplos como Uber, Netflix, Airbnb, Zipcar e até mesmo sites de venda de produtos usados para representá-la (JOHN, 2013; BELK, 2014b; PERREN; GRAUERHOLZ, 2015; AKBAR; MAI; HOFFMANN, 2016; COCKAYNE, 2016; ERTZ; DURIF; ARCAND, 2016b). Esse desentendimento e a apreensão conceitual por meio de protótipos têm suscitado o surgimento de sérias críticas à possibilidade da real existência de uma economia do compartilhamento.

Os casos e protótipos geralmente apresentados como representantes da economia do compartilhamento são questionados por Bardhi e Eckhardt (2012, p. 881). Para as autoras, grande parte dos exemplos utilizados para representar o conceito não se ajustam às fracas definições disponibilizadas pelos trabalhos, o que as levou à criação de um outro conceito, capaz de sustentar a inovatividade dessas novas plataformas virtuais: economia baseada em acesso. Segundo as autoras, "[...] ao invés de comprar e possuir coisas, consumidores querem acesso a bens e preferem pagar pela experiência de acessá-los temporariamente". A economia do compartilhamento para as autoras, de acordo com os exemplos a ela atribuídos, não passam de um pensamento platônico de engajamento coletivo em causas supostamente altruístas. Nesse ponto, tecem duras críticas especificamente ao conceito e ao embasamento teórico proposto por Belk (2010; 2014b).

Na perspectiva da economia do acesso o importante para o consumidor é o serviço prestado, desconsiderando a relevância de orientações sustentáveis ou altruístas. 0 consumidor, portanto, é entendido sobre móbiles estritamente utilitários. O que mudou do consumidor da economia do acesso para o consumidor dos modelos de mercado tradicionais foi apenas a predisposição à manutenção da propriedade de um bem a longo prazo - e, consequentemente, o seu nível de materialismo. O consumidor troca, portanto, a posse dos bens pela otimização de seus recursos econômicos. Para a abordagem da economia baseada no acesso, plataformas como Uber e Airbnb, sempre polêmicas nas discussões do conceito de economia do compartilhamento, se encaixariam perfeitamente sob o seu escopo. Eckhardt e Bardhi (2016), contudo, não negam a existência de categorias de consumo baseadas no compartilhamento, concebendo-as como um subgrupo das práticas de consumo baseadas no acesso. Para elas, são casos mais raros e com pouco apelo sobre o grande público. 
Os mercados baseados na economia do acesso "[...] são caracterizados por transações individualizadas, de curto-prazo, imediatas e episódicas, onde trocas baseadas na eficiência dos custos são motivadas pelo autointeresse e geração de lucro" (ECKHARDT; BARDHI, 2016, p. 217). Todas essas características são comuns às trocas econômicas tradicionais e pouco ou nada se diferem das práticas de mercado realizadas até então (BAGOZZI, 1975; HOUSTON; GASSENHEIMER, 1987). Essa perspectiva, contudo, contrasta com o que comumente se define como economia do compartilhamento, uma vez que as práticas de mercado baseadas nessa perspectiva estariam ancoradas em outra categoria de interação, isto é, as trocas comunais e no próprio compartilhamento (BELK, 2010; 2014b). Tal categoria de troca seria definida como uma obrigação especial que seus membros sentem de se preocupar com o bem-estar de outrem (FISKE, 1992; FOLKES, 2002).

\section{DEFINIÇÕES DE ECONOMIA DO COMPARTILHAMENTO}

As definições tradicionais de economia do compartilhamento não delimitam bem a fronteira do que corresponde uma prática econômica tradicional e uma prática colaborativa, aceitando praticamente qualquer ação entre agentes de mercado realizada em pares ou grupos e que compartilhem de um bem ou serviço em comum. Esse é o caso da definição de Felson e Speath (1978). Os autores utilizam a expressão consumo colaborativo - circunscrita pela economia do compartilhamento (BELK, 2014b) - para demonstrar como as pessoas podem se engajar em ações de mercado sem necessariamente seguir as regras de conduta esperadas por um agente econômico padrão.

Para os autores, as normas econômicas são subvertidas quando "[...] uma ou mais pessoas se engajam na realização de atividades conjuntas com outras pessoas para o consumo de bens ou serviços econômicos" (FELSON; SPEATH, 1978, p. 614). As limitações do escopo dessa definição são imprecisas, pois uma viagem em um transporte coletivo, nesse caso, poderia muito bem ser delimitada pelos princípios da economia do compartilhamento. Embora os passageiros dividam o mesmo serviço, uma vez que desistem de comprar cada um o seu próprio veículo, andar de ônibus da maneira habitual como praticamos não se caracterizaria com um exemplo de colaboração ou compartilhamento. Existe, de fato, um compartilhamento involuntário momentâneo, mas tão frouxo quanto o compartilhamento de um idioma ou do oxigênio - insuficiente para configurá-lo como tal (BELK, 2010). O exemplo dos condomínios das grandes cidades também se configura como prática de compartilhamento involuntário, embora de longo prazo. Outro caso que exemplifica a incongruência entre um consumo simultâneo coletivo e um consumo em uma economia do compartilhamento é o das transmissões televisivas. 0 fato de várias pessoas poderem assistir um mesmo programa ao mesmo tempo não o caracteriza como um consumo diferenciado. Essa má interpretação ocorre porque há uma tendência recorrente de se relacionar o compartilhamento apenas à ideia de bens públicos ou não rivais - aqueles em que o consumo de uma pessoa não exclui a possibilidade de consumo de outra, como parques, segurança pública etc. (KAUL; MENDOZA, 2003).

Outros conceitos de economia do compartilhamento a têm associada à orientação ideológica dos seus agentes, principalmente à responsabilidade socioambiental e ao desenvolvimento sustentável (HEINRICHS, 2013; MORLIGHEM, 2014; HAMARI; SJÖKLINT; 
UKKONEN, 2015; ERTZ; DURIF; ARCAND, 2017; CHERRY; PIDGEON, 2018). Nessa perspectiva, o consumo de produtos verdes, o reaproveitamento de materiais usados, a compra de itens de segunda mão e a aquisição de mercadorias produzidas na própria região se caracterizariam como práticas centrais da economia do compartilhamento. Apesar de louvável a busca por um conceito que aborde valores nobres e necessários à sociedade, a economia do compartilhamento não pode ser reduzida a tal perspectiva ou pensada sistemicamente a partir desses parâmetros. Isso porque, de modo geral, há apenas a valorização de práticas sustentáveis, mas não de práticas coletivas que se valem de conceitos como a colaboração, a reciprocidade ou o compartilhamento. Embora tenha o intuito de promover o bem-estar socioambiental, o consumo verde ou sustentável é geralmente realizado por meio do engajamento em práticas individuais, deslocando-se em parte da concepção de um consumo coletivo.

Para contornar essa superapreensão da economia do compartilhamento, outras definições tentam delimitar o conceito para abranger apenas práticas econômicas em grupo, evitando-se o contato direto com uma empresa formal. É o caso da definição de Botsman e Rogers (2011), que indica que a colaboração ocorre quando pessoas decidem participar de compartilhamentos, escambos, trocas, aluguéis e coletividades organizadas. Nesse caso, o problema surge em se definir o que seria uma empresa formal e qual a amplitude de ação nessas relações. Em muitos casos, é necessário a existência de uma empresa formal a priori, como indústrias de extração e produção, para a confecção dos itens utilizados no circuito de comércio da economia do compartilhamento. Para que haja trocas entre os consumidores, os produtos, na grande maioria dos casos, foram confeccionados em um primeiro circuito de produção, proveniente da economia das "empresas formais". Igualmente, diversas organizações intermediam o contato entre consumidores e outros agentes do mercado, se configurando elas mesmas como empresas formais.

Urge, portanto, que novas definições e classificações dos protótipos empíricos sejam levantadas para a organização conceitual dos fenômenos relacionados à economia do acesso e à economia do compartilhamento. Para tal, é necessário o levantamento de conceitos e pressupostos basilares que nos permitam inter-relacionar as práticas e modelos das duas economias, apresentados a seguir.

\section{PROBLEMATIZANDO A CONCEITUAÇÃO DE ECONOMIA DO COMPARTILHAMENTO}

Um problema decisivo nas definições das práticas da economia do compartilhamento é a ênfase excessiva sobre os seus elementos constituintes, sejam produtos, serviços, consumidores ou empresas. Em geral, as definições buscam mostrar a independência do consumidor em relação ao modelo tradicional de compra e venda - modelo de mercado convencional -, revelando um consumidor mais autônomo e livre para se engajar em relações econômicas diferenciadas (BELK, 2010, 2014a; ECKHARDT; BARDHI, 2016). Entretanto, a retratação de emancipação do consumidor é realizada, normalmente, por meio de uma empreitada individualizada, além de uma interatividade isolada e episódica. É necessário que se pese, em primeiro lugar, a centralidade das relações, seja entre pessoas, dinheiro ou sociedade, na formação do conceito de economia do compartilhamento. Essa é, inclusive, uma questão basilar na construção conceitual de qualquer fenômeno (WHITEHEAD, 1985). 
De fato, há um problema intrínseco aos conceitos, uma vez que eles são descontínuos e fixos, e, como tais, são incapazes de capturar uma realidade sempre mutável. Do mesmo modo, como elucida Whitehead (1985), por meio da Fallacy of Misplaced Concreteness, há um predomínio de explicações conceituais que se valem de definições que tentam apreender uma suposta essência do objeto, desvalorizando o que o autor considera de mais importante: suas relações. 0 esforço de conceituação, portanto, deve tentar alcançar o nível relacional do "objeto", inclusive com o próprio "observador".

O foco excessivo nos objetos e atores que compõem as práticas da economia do compartilhamento desvirtua o foco do que realmente importa na sua construção: a relação entre pessoas, suas interações com a materialidade dos objetos trocados. 0 elemento mais importante que deve constar na formação do conceito de economia do compartilhamento é o caráter dinâmico e cíclico que essa prática suscita. Esse é um ponto de partida fundamental para uma releitura do inevitável jogo dos conceitos, controlado pelos impulsos intelectualistas, isto é, a forma pela qual comumente tomamos sentido de nossas experiências através de conceitos (TSOUKAS; CHIA, 2002). Tais impulsos acabam por originar um aprisionamento que fatalmente condicionará a percepção da realidade a uma imobilidade estrutural e descontínua.

O processo de criação de um conceito, segundo Tsoukas e Chia (2002), deve se iniciar pela seleção de protótipos - ou seja, a escolha de fenômenos empíricos que Ihe sirvam de exemplo -, mas não se encerrar nele. Em geral, os protótipos selecionados estão radialmente estruturados, seguindo uma ordem de importância que se dispõe desde os exemplos centrais, de maior representação, até alcançar os protótipos mais marginais, localizados às raias delimitadas pelo conceito. Nesse ponto, os autores apresentam o caráter complementar das abordagens sinóptica - essencialmente moderna -, e performativa de caráter pós-moderno -, na criação de novos conceitos. Ao passo que na primeira as preocupações giram em torno da ação central realizada, buscando encontrar a "grande figura" que sintetiza o fenômeno, o segundo procura atentar-se às microações e ao contínuo processo de realizações que modelam o fenômeno indefinidamente. A utilização conjunta das duas abordagens possui uma dupla vantagem, pois tanto permite que o conceito criado não se perca em um esforço vago de abstração, dando-Ihe profundidade e dinâmica, quanto possibilita a seleção de exemplos empíricos adequados.

No caso na economia do compartilhamento, os agentes do mercado podem ampliar as suas possibilidades de ação, passando a exercer múltiplas funções. A antiga fronteira entre consumidor e empresa, que os caracterizava como elementos individualizados que disputam pela maximização de seus recursos financeiros em transações econômicas marcadas pela negociação e o jogo de poder (FOLKES, 2002), passa a ser rompida sob o signo da economia do compartilhamento. A perspectiva econômica não deixa de existir nessa nova economia, mas as tradicionais formas de encarar o lucro e as recompensas de mercado são reorganizadas; e com elas os papéis e funções desempenhados pelos seus antigos agentes (BOTSMAN; ROGERS, 2011; ERTZ; DURIF; ARCAND, 2017). Os benefícios financeiros, predominantes até então, passam a coexistir com outras formas de ganho, provenientes de uma categoria de benefícios relacionais ainda maior, que, em muitos casos, não se restringem a meras relações qui pro quo (BELK, 2014b). 
É importante ressaltar que relações sociais mediadas por compensações financeiras são típicas das sociedades modernas e se diferenciam das demais relações sociais porque seus atores apresentaram, segundo Simmel (2005), um acentuado caráter blasé, ou seja, um embotamento da distinção entre coisas e pessoas, uma vez que tudo parece ser reduzido ao mero valor financeiro. A relação dos agentes econômicos com o dinheiro, portanto, é um fator relevante na análise das práticas de mercado suscitadas pelas economias de acesso e de compartilhamento.

Nesse sentido, a economia do compartilhamento se caracteriza por ser mais dinâmica, flexível e menos institucionalizada do que os mercados tradicionais; uma vez que suas práticas se organizam por meio de interações, em geral, pouco estruturadas (BOTSMAN; ROGERS, 2011; BELK, 2014b; ERTZ; DURIF; ARCAND, 2017). Sob os contornos da economia do compartilhamento, práticas mercadológicas e não-mercadológicas emergem conjuntamente. Entretanto, ao contrário dos mercados tradicionais, o foco das práticas da economia do compartilhamento não recai sobre o espectro financeiro, mas em ganhos relacionais (BELK, 2014b). Embasando-se em tais concepções, e guiando-se pelas definições de economia do compartilhamento traçadas por Felson e Speath (1978), Botsman e Rogers (2011), portanto, este estudo utiliza como conceito de economia do compartilhamento a perspectiva em que pessoas sustentam relações socioeconômicas entre si pautando-se, principalmente, em benefícios relacionais - sejam eles com pessoas ou comunidades, por exemplo. Para tal, prescindindo de contratos formais, interatuam alternando, geralmente por meio de agentes facilitadores, os papéis e práticas econômicas entre seus membros.

\section{TIPOLOGIA DOS MERCADOS DE ACESSO - ECONOMIA DO COMPARTILHAMENTO EECONOMIA DO ACESSO}

A economia do compartilhamento é um ramo da economia que se originou apenas recentemente, funcionando como um conceito guarda-chuva que compreende as atividades de mercado que fogem das relações orientadas pelo mero utilitarismo econômico (BELK, 2010; 2014b). Dentro dessa perspectiva, práticas econômicas sui generis contribuem para a expansão do próprio entendimento de mercado. Como todo fenômeno econômico, o mercado das trocas comerciais - também conhecidas como trocas rígidas - é acima de tudo um fenômeno social (SCHUMPETER, 1961); portanto, sujeito às vicissitudes do contexto sociológico onde está inserido. $\mathrm{O}$ surgimento (ou ressurgimento) de práticas que fogem à ortodoxia do mercado capitalista demonstram que não há um mercado natural, com características imutáveis e definidas a priori, mas uma pluralidade de mercados com lógicas e orientações diferenciadas (POLANYI, 2012; LAVILLE, 2003). Baseando-se nessa perspectiva, uma aproximação entre a economia solidária (abordagem que tangencia a economia do compartilhamento) e a economia plural é realizada por Silva, Ramalho e Rigo (2016).

Em contraste, a economia do acesso não possui fundamentos ontológicos distintos dos mercados tradicionais. Entretanto, suas práticas se caracterizam como ações que, de alguma maneira, reformulam os modelos econômicos convencionais, seja por meio da oferta de novos produtos ou serviços, ou promovendo modificações nos já existentes (ECKHARDT; BARDHI, 2015, 2016). O que ambos os modelos de relações econômicas possuem em comum é o escopo na ampliação do acesso. Tanto a economia do compartilhamento quanto 
a economia do acesso possuem como objetivo o desenvolvimento de modelos de negócio ou de relações sociais que incrementem as possibilidades dos agentes de mercado, facilitando as suas interações, trocas ou compartilhamentos. 0 acesso, portanto, é o elemento central que une as duas economias. Obviamente, vieses de consumo, como a busca por status, construção de identidade, distinção ou diferenciação (BOURDIEU, 1984; BELK, 1988; 2013; BAUDRILLARD, 2011), permanecem presentes nos dois modelos. Entretanto, não desloca a centralidade da ampliação de acesso em ambos os casos.

No caso específico da economia do acesso, assim como no mercado tradicional, as relações são baseadas na maximização do auto-interesse - pressuposto central do utilitarismo econômico (BENTHAM, [1789] 1996; MILL, [1863] 2005). Os agentes, sob essa perspectiva, são guiados por interesses próprios e procuram maximizar a razão entre custos e benefícios (FISKE, 1992). O objetivo final de qualquer indivíduo é o alcance de conceitos atemporais, geralmente relacionados à felicidade, prazer ou poder, através de uma relação instrumental e racionalizada com outros indivíduos e objetos (HOBBES, [1651] 1999; MILL, [1863] 2005). Em outras palavras, o elemento norteador das relações econômicas seria, como em qualquer outra interação social, a maximização dos ganhos individuais (MILL, [1863] 2005).

Apesar do utilitarismo não ser sobrepujado na economia do acesso (cf. BARDHI; ECKHARDT, 2012; ECKHARDT; BARDHI, 2016), o indivíduo passa a dividir momentaneamente um bem ou serviço, ainda que de forma involuntária, cuja posse poderia jamais ser partilhada. Nessa perspectiva, benefícios sociais podem ser alcançados direta ou indiretamente, contribuindo para eventuais ganhos de ordem socioambiental. Sob os contornos da economia do acesso é possível destacar dois modelos constituintes em que se predomina a fundamentação utilitária. Diferem dos modelos tradicionais, contudo, pelo fato de possuírem forte aporte tecnológico, o que modifica profundamente a relação entre os agentes de mercado, quais sejam: Modelos baseados em appficação e Modelos disruptivos.

\section{MODELOS BASEADOS NA APPFICAÇÃO}

Caracterizam-se pela insubstituível presença do componente tecnológico. Antigas formas de relacionamento entre agentes de mercado são remodeladas e, de certa maneira, potencializadas por meio dos atuais avanços tecnológicos. Dentre eles, destacam-se o desenvolvimento de aplicativos para tablets e smartphones, que permitiram interações mais dinâmicas e em tempo real. A Web 2.0 foi um marco na promoção desses modelos, pois permitiu a ampliação das relações sociais, possibilitando a criação de redes econômicas com amplitude global.

Exemplos de plataformas e aplicativos que servem de protótipo para esse modelo são o Uber, o ZipCar e a Estante Virtual. Em todos os casos, produtos ou serviços semelhantes já eram oferecidos no mercado. Entretanto, tais plataformas conseguiram impulsionar os seus mercados oferecendo formas mais modernas de integrar agentes de mercado. 


\section{MODELOS DISRUPTIVOS}

Os modelos disruptivos, por outro lado, não se caracterizam apenas por apresentarem forte embasamento tecnológico, mas por modificarem profundamente antigos modelos de negócio. Demandas até então suprimidas ou inexistentes são criadas, desenvolvendo novos mercados. Com eles, novos modelos, conceitos e relações emergem, promovendo uma mudança radical em certos setores da economia (CHRISTENSEN et al., 2015).

Um dos principais representantes dessa categoria é a plataforma de entretenimento Netflix, por ter promovido uma reorganização na forma das pessoas consumirem filmes e séries - sendo responsável pela substituição da compra ou aluguel por uma assinatura mensal que disponibiliza um extenso inventário de filmes e séries online (CHRISTENSEN, et al., 2015). Do mesmo modo, destacam-se as plataformas digitais que permitem a conexão entre agentes de mercado que buscam não apenas comprar, mas vender e trocar produtos. É o caso dos sites OLX e Kijiji que, devido à constante venda e troca de produtos usados, possuem papel importante na reutilização de produtos de segunda-mão e na consequente redução do uso dos recursos naturais (ERTZ; DURIF; ARCAND, 2016a).

Por outro lado, ao tratarmos da economia do compartilhamento, novos pressupostos metateóricos emergem. Passa-se a questionar a singularidade dos antigos conceitos utilitaristas, como a otimização dos recursos pessoais, orientação individualista baseada no autointeresse, felicidade coletiva racionalizada e fruto da soma dos prazeres individuais (cf. HOBBES, [1651] 1999; BENTHAM, [1789] 1996; MILL, [1863] 2005). Tais fundamentos perdem o caráter de imanência, passando a representar perspectivas peculiares de comportamento e orientação mercadológica. São assim, apenas mais uma forma de se comportar em meio às múltiplas relações sociais (CAILLÉ, 2001; LAVILLE, 2003). A economia do compartilhamento embasa-se, em contraste, sobre pressupostos antiutilitaristas para o desenvolvimento das suas relações e práticas de mercado. As interações entre os seus agentes são regidas pela contraditória obrigação de retribuir (MALINOVSKY, 2005); caracterizando-se, portanto, como uma obrigação desobrigada presente no contínuo ciclo da dádiva composto pela tríade dar, receber, retribuir (MAUSS, 2003).

Ao passo que para a perspectiva utilitarista todas as interações ocorridas na sociedade, sejam econômicas, políticas, jurídicas etc., se caracterizam como simples atos racionais de troca, para a abordagem antitutilitarista trata-se, no fundo, de misturas. "Misturam-se as almas nas coisas, misturam-se as coisas nas almas. Misturam-se as vidas, e assim as pessoas e as coisas misturadas saem cada qual de sua esfera e se misturam: o que é precisamente o contrato e a troca" (MAUSS, 2003, p. 2012). A atmosfera de rivalidade, isolamento individual e calculismo econômico apresentada pela filosofia utilitarista, portanto, não seria uma condição fundamental do comportamento humano, mas apenas uma das muitas possíveis. As misturas decorrentes das trocas, para Mauss (2003), não se restringem à esfera econômica, mas se expandem para abranger outras dimensões do ser. Seríamos compreendidos, portanto, por outro viés ontológico, menos economicista, mais complexo e integrado a um sistema social maior (POLANYI, 2012).

De acordo com a forma dos seus agentes se relacionarem, é possível dividir a economia do compartilhamento em dois modelos: Modelos híbridos e Modelos colaborativos. 


\section{MODELOS HÍBRIDOS}

Embora nos modelos híbridos as relações entre os agentes de mercado não sigam móbiles estritamente utilitários, as interações entre as pessoas são mediadas pela presença pecuniária. Se caracterizam como práticas em que o aspecto financeiro divide a centralidade com a promoção de benefícios sociais diretos, posicionando-se em um meio termo entre o dom e as práticas de mercado convencionais (SCARABOTO, 2015). Dessa forma, tanto empresas quanto consumidores se orientam por meio de comportamentos pró-sociais. É importante ressaltar, entretanto, que não se caracterizam como ações filantrópicas, mas como estratégias de negócio autossustentáveis que facultam o desenvolvimento de causas sociais específicas, como a proteção do meio ambiente, diminuição da pobreza, estímulo à produção local etc., ao passo que ofertam os seus produtos ou serviços. Nessa perspectiva, os benefícios relacionais podem não ser peer-to-peer (pessoa para pessoa), mas entre uma pessoa e a sua comunidade.

O financiamento coletivo por exemplo, mais conhecido como crowdfunding, pode ser considerado uma prática circunscrita pelos modelos híbridos (HAMARI; SJÖKLINT; UKKONEN, 2015). Essa prática de financiamento coletivo representa uma atividade de intensa colaboração, além de possuir um alto apelo social. Cumpre salientar que, em alguns casos, tais financiamentos podem se configurar como modelos colaborativos, pois, apesar de envolverem dispêndios financeiros, não há uma obrigatoriedade direta de retorno. Um exemplo de empresa híbrida é a inglesa WWOOF (World-Wide Opportunities on Organic Farms), orientada à realização de ações sociais - ainda que se envolva em trocas financeiras. Do mesmo modo, também é possível citar como modelo híbrido o caso das bicicletas compartilhadas, famosas nas grandes capitais brasileiras. $O$ aluguel de bicicletas por curtos períodos propiciou o surgimento de um grande e atrativo negócio, geralmente conduzido ou intermediado pelo setor público. Em geral, tais iniciativas buscam estimular o consumo ou a produção consciente, bem como desenvolver práticas econômicas sustentáveis.

\section{MODELOS COLABORATIVOS}

Os modelos colaborativos se diferenciam de todos os demais modelos por não apresentarem trocas em que há uma obrigação imediata de retribuir. Do mesmo modo, as relações entre os seus agentes não são mediadas por trocas pecuniárias. 0 aspecto financeiro pode surgir de forma indireta, mas não rege a relação entre os seus membros. Compreendem, de fato, as relações sociais que mais se distanciam do utilitarismo econômico, aproximando-se, assim, dos conceitos centrais do antiutilitarismo (CAILLÉ, 2001; LAVILLE, 2003; MAUSS, 2003).

Um protótipo que representa tais modelos são as famílias. Assim como observam Felson e Speath (1978) e Belk (2010), as relações familiares são marcadas por uma preocupação que foge às normas e regularidades das trocas econômicas tradicionais, uma vez que há uma preocupação com o bem-estar comum que transcende a esfera financeira; assim o é também o hábito de compartilhar comida com vizinhos, amigos ou a qualquer um que precise (WIDLOCK, 2004). Do mesmo modo, as trocas não mediadas por valores pecuniários, ou seja, escambo de produtos (e.g., CiroSel) ou serviços (e.g., Blive), também 
podem ser consideradas práticas compreendidas pelos modelos colaborativos, uma vez que distorcem o caráter blasé das relações sociais apontado por Simmel (2005).

Em se tratando de ambientes online, um exemplo de plataforma virtual colaborativa é o famoso Wikipédia. Casos como esse são denominados por Perren e Grauerholz (2015) de comunidades de inovação coletiva, cuja principal característica diz respeito à colaboração entre os usuários para a criação e desenvolvimento de conteúdos virtuais compartilhados livremente; relacionando-se, assim, tanto à esfera produtiva quanto à dimensão do consumo. Outro exemplo de plataforma colaborativa é o Couchsurfing, uma vez que os seus usuários se valem apenas de benefícios relacionais para obter estadias nos "sofás" das residências de outros usuários. Compensações financeiras, inclusive, são desestimuladas e repreendidas pela plataforma (MOLZ, 2013). Apesar de não estimular transações financeiras, tais plataformas não deixam de gerar valor econômico por se constituírem de grandes redes de relacionamento e possuírem abrangência global. Prova disso foi a recente mercadização do Couchsurfing, obtendo milhões de dólares em financiamento privado anualmente (PERLROTH, 2011; LAPOWSKY, 2012).

É importante ressaltar que, a depender de particularidades próprias de cada relação, práticas supostamente definidas como formas de compartilhamento podem se caracterizar ou não como modelos colaborativos. Esse é o caso do compartilhamento de um carro entre integrantes de uma mesma família ou para colocar à disposição de uma grande companhia, como o Uber ou o Zipcar (KATSEV, 2003). Os dois exemplos se configuram como modos completamente distintos de compartilhar.

Além dos elementos supracitados, também se revelam, para a presente tentativa de tipificação, seis derivações dos modelos da economia do acesso e da economia colaborativa. Esse estrato se fundamenta nas relações financeiras como fator determinante de classificação. No caso da economia do acesso, tanto os modelos baseados na "appficação" quanto os modelos disruptivos podem gerar práticas econômicas baseadas apenas no lucro tradicional (e.g., Uber, AirBnb e Netflix) ou na combinação de lucro com benefícios sociais indiretos (e.g., Estante Virtual e CrediAmigo). No segundo caso, os interesses sociais não se caracterizam como objetivos centrais das empresas, mas acabam por auxiliar, por exemplo, no desenvolvimento social, na redução de poluentes tóxicos da natureza, na reutilização de produtos usados etc.

Quanto à economia colaborativa, há dois desdobramentos para cada um de seus modelos. No caso dos modelos híbridos, ambas as práticas econômicas produzem benefícios sociais diretos, ou seja, possuem como escopo alguma responsabilidade socioambiental específica. O que as diferencia, contudo, são os ganhos pecuniários, que podem se caracterizar como lucros convencionais (e.g., coworking) ou receitas suficientes apenas para promover a manutenção das atividades (e.g., WWOFF e bicicletas compartilhadas). Por outro lado, as práticas econômicas compreendidas tanto pelo macro sharing (macrocompartilhamento) quanto pelo micro sharing (microcompartilhamento) não envolvem compensações financeiras diretas. $\mathrm{O}$ que as diferem é apenas a dimensão das relações entre os atores envolvidos e o potencial para gerar valor econômico. Ao passo que no macro sharing as interações alcançam, ou podem alcançar, proporções globais (e.g., Couchsurfing, CiroSel, BlaBlaCar, CrossBooking e Blive) - e, portanto, passíveis de criação de algum valor econômico -, no 
micro sharing as ligações entre os atores são bem localizadas, tais como as famílias e os grupos de amigos - possuindo pouco ou nenhum potencial econômico.

Com base nas acepções teóricas expostas e dos protótipos e modelos de mercados apresentados, são sumarizadas no Quadro 1 as divergências entre as práticas compreendidas pela economia do acesso e pela economia do compartilhamento.

Quadro 1 - Distinção entre Economia do Acesso e Economia do Compartilhamento

\begin{tabular}{|c|c|c|c|}
\hline Classes & Atributos & Economia do Acesso & Economia do Compartilhamento \\
\hline \multirow[t]{2}{*}{$\begin{array}{l}\text { Bases } \\
\text { Metateóricas }\end{array}$} & $\begin{array}{l}\text { Perspectiva Onto- } \\
\text { lógica }\end{array}$ & $\begin{array}{l}\text { Sistêmica - foco econômico e } \\
\text { "racional", baseado na busca } \\
\text { por uma utilidade intrínseca aos } \\
\text { produtos e maximização de uma } \\
\text { função econômica baseada no } \\
\text { custo/benefício }\end{array}$ & $\begin{array}{l}\text { Processual - foco nas relações e } \\
\text { desempenho de lógicas múltiplas } \\
\text { (inclusive econômica) }\end{array}$ \\
\hline & $\begin{array}{l}\text { Perspectiva Episte- } \\
\text { mológica }\end{array}$ & Utilitarismo Econômico & Antiutilitarismo \\
\hline \multirow{5}{*}{$\begin{array}{l}\text { Organização } \\
\text { de Mercado }\end{array}$} & Modelo de Mercado & $\begin{array}{l}\text { Naturalizado, autorregulado e } \\
\text { orientado principalmente pela } \\
\text { lógica econômica }\end{array}$ & $\begin{array}{l}\text { Criativo, mutável e plural, moldado } \\
\text { pelas relações sociais }\end{array}$ \\
\hline & Relações de troca & $\begin{array}{l}\text { Relações simétricas e "fechadas" } \\
\text { - começo, meio e fim. Presença de } \\
\text { contratos formais }\end{array}$ & $\begin{array}{l}\text { Relações cíclicas e Abertas - dar, } \\
\text { receber e retribuir. Ausência de } \\
\text { contratos formais. }\end{array}$ \\
\hline & $\begin{array}{l}\text { Perspectiva Econô- } \\
\text { mica }\end{array}$ & $\begin{array}{l}\text { Central, relegando demais aspectos } \\
\text { à marginalidade }\end{array}$ & $\begin{array}{l}\text { Periférica, embora ainda impor- } \\
\text { tante }\end{array}$ \\
\hline & $\begin{array}{l}\text { Mecânica Produ- } \\
\text { tiva }\end{array}$ & $\begin{array}{l}\text { Funções de produção e consumo } \\
\text { bem delimitadas e não intercam- } \\
\text { biáveis }\end{array}$ & $\begin{array}{l}\text { Baseia-se nos conceitos de } \\
\text { cocriação e prosumption. Funções } \\
\text { intercambiáveis }\end{array}$ \\
\hline & Operacionalização & $\begin{array}{l}\text { Foco no produto ou serviço: Reifi- } \\
\text { cação e isolamento dos objetos de } \\
\text { análise }\end{array}$ & $\begin{array}{l}\text { Foco nas relações: processo contí- } \\
\text { nuo e mudança de posicionamento }\end{array}$ \\
\hline \multirow{6}{*}{$\begin{array}{l}\text { Aspectos } \\
\text { Individuais }\end{array}$} & $\begin{array}{l}\text { Identidade dos } \\
\text { Agentes }\end{array}$ & $\begin{array}{l}\text { Unitária - consumidor x produtor } \\
\text { (organização) }\end{array}$ & $\begin{array}{l}\text { Fragmentada - consumidor, produ- } \\
\text { tor, articulador da rede etc. }\end{array}$ \\
\hline & $\begin{array}{l}\text { Hierarquia de } \\
\text { Papéis }\end{array}$ & $\begin{array}{l}\text { Fronteiras bem delimitadas. } \\
\text { Organizações com maior poder nas } \\
\text { relações }\end{array}$ & $\begin{array}{l}\text { Ausência de fronteiras rígidas e } \\
\text { redução da desigualdade de poder }\end{array}$ \\
\hline & $\begin{array}{l}\text { Relações Indivi- } \\
\text { duais }\end{array}$ & $\begin{array}{l}\text { Interações estruturadas, hierarqui- } \\
\text { zadas e papéis bem definidos }\end{array}$ & $\begin{array}{l}\text { Relações flexíveis, instabilidade e } \\
\text { papéis mutáveis }\end{array}$ \\
\hline & $\begin{array}{l}\text { Acesso à Informa- } \\
\text { ção }\end{array}$ & $\begin{array}{l}\text { Limitado e assimétrico - organi- } \\
\text { zações detêm mais poder sobre a } \\
\text { informação }\end{array}$ & $\begin{array}{l}\text { Ampliado - consumidores cole- } \\
\text { tivamente detêm poder sobre as } \\
\text { informações }\end{array}$ \\
\hline & $\begin{array}{l}\text { Relação com a } \\
\text { Propriedade }\end{array}$ & $\begin{array}{l}\text { Individualizada - uma pessoa ou } \\
\text { uma organização tem a proprieda- } \\
\text { de sobre o bem }\end{array}$ & $\begin{array}{l}\text { Coletiva - embora, em geral, } \\
\text { apenas uma pessoa ou grupo de } \\
\text { pessoas possui um maior poder } \\
\text { sobre o bem }\end{array}$ \\
\hline & Uso dos Produtos & A curto e curtíssimo prazos & Médio, curto ou curtíssimo prazo \\
\hline
\end{tabular}




\begin{tabular}{|c|c|c|c|}
\hline Classes & Atributos & Economia do Acesso & Economia do Compartilhamento \\
\hline \multirow{4}{*}{$\begin{array}{l}\text { Aspectos } \\
\text { Sociais }\end{array}$} & Perspectiva Central & Individualismo & Alteridade \\
\hline & Relações Sociais & $\begin{array}{l}\text { Entre consumidor e organização - } \\
\text { reduzido ou nenhum contato com } \\
\text { outras pessoas }\end{array}$ & $\begin{array}{l}\text { Entre cocriadores e proconsumido- } \\
\text { res - contato moderado ou de alta } \\
\text { intensidade, físico ou virtual, com } \\
\text { outras pessoas }\end{array}$ \\
\hline & $\begin{array}{l}\text { Comunidades de } \\
\text { Consumo }\end{array}$ & $\begin{array}{l}\text { Inexistente ou extremamente } \\
\text { abertas, definidas pelo comparti- } \\
\text { Ihamento de intenções }\end{array}$ & $\begin{array}{l}\text { Abertas e flexíveis, definidas por } \\
\text { compartilhamento de práticas e } \\
\text { intenções - tribos e grupos de } \\
\text { consumo }\end{array}$ \\
\hline & $\begin{array}{l}\text { Formas de Sociali- } \\
\text { zação }\end{array}$ & $\begin{array}{l}\text { Trocas mercadológicas de } \\
\text { commodities }\end{array}$ & $\begin{array}{l}\text { Relações mercadológicas, de } \\
\text { compartilhamento e/ou de recipro- } \\
\text { cidade }\end{array}$ \\
\hline \multirow{2}{*}{ Protótipos } & Radiais & Uber, Netflix, Zipcar & Família, Couchsurfing, Wikipedia \\
\hline & Periféricos & AirBnb, OLX & $\begin{array}{l}\text { Kijiji, Coworking, Crowdfunding, } \\
\text { WWOOF }\end{array}$ \\
\hline
\end{tabular}

Com efeito, a visualização tipológica (Figura 1) das semelhanças e divergências descritas em texto até então se faz necessária como elemento de apresentação desta proposta, revelando como principais pontos chave desta taxonomia, do geral para o mais específico: i) a dimensão ontológica; ii) os modelos de mercado e iii) relações socioeconômicas.

Utilitarismo

\begin{tabular}{|c|c|c|}
\hline $\begin{array}{c}\text { Dimensão } \\
\text { Ontológica }\end{array}$ & Economia do Acesso & $\begin{array}{c}\text { Economia do } \\
\text { Compartilhamento }\end{array}$ \\
\hline
\end{tabular}

\begin{tabular}{||c|c|c|c|c|}
\hline $\begin{array}{c}\text { Modelos de } \\
\text { Mercado }\end{array}$ & $\begin{array}{c}\text { Modelos } \\
\text { "Appficaçăo" }\end{array}$ & $\begin{array}{c}\text { Modelos } \\
\text { Disruptivos }\end{array}$ & $\begin{array}{c}\text { Modelos } \\
\text { Hibridos }\end{array}$ & $\begin{array}{c}\text { Modelos } \\
\text { Colaborativos }\end{array}$ \\
\hline
\end{tabular}

\begin{tabular}{|c|c|c|c|c|c|c|c|c|}
\hline $\begin{array}{c}\text { Relações } \\
\text { Financeiras }\end{array}$ & $\begin{array}{l}\text { Lucro } \\
\text { Tradicional }\end{array}$ & $\begin{array}{l}\text { Lucro + Ben. } \\
\text { Sociais Indiretos }\end{array}$ & $\begin{array}{l}\text { Lucro } \\
\text { Tradicional }\end{array}$ & $\begin{array}{l}\text { Lucro + Ben. } \\
\text { Sociais Indiretos }\end{array}$ & $\begin{array}{l}\text { Lucro + Ben. } \\
\text { Sociais Diretos }\end{array}$ & $\begin{array}{c}\text { Auto } \\
\text { Sustentável + } \\
\text { Ben. Sociais Dir. }\end{array}$ & Macro Sharing & Micro Sharing \\
\hline $\begin{array}{l}\text { Protótipos } \\
\text { Radiais }\end{array}$ & $\begin{array}{l}\text { Uber } \\
\text { Airbnb } \\
\text { ZipCar }\end{array}$ & Estante Virtual & Netflix & $\begin{array}{l}\text { CrediAmigo } \\
\text { UberPool }\end{array}$ & $\begin{array}{l}\text { Coworking } \\
\text { OLX } \\
\text { Kijiji }\end{array}$ & $\begin{array}{l}\text { Crowdfunding } \\
\text { WWOF }\end{array}$ & $\begin{array}{l}\text { Couchsurfing } \\
\text { Wikipedia } \\
\text { CiroSel }\end{array}$ & $\begin{array}{l}\text { Familias } \\
\text { Vizinhança } \\
\text { Colaborativa }\end{array}$ \\
\hline
\end{tabular}

Figura 1- Tipologia dos mercados de acesso 


\section{CONSIDERAÇÕES FINAIS}

O objetivo de construção de uma taxonomia é, acima de tudo, um esforço preliminar e incompleto, uma vez que não encerra as possibilidades de classificação e de estudo dos sempre inovativos e mutáveis protótipos do mundo empírico. Buscamos apresentar uma comparação de duas importantes vertentes ontológicas sobre o mercado atual, discutindo-se os elementos que aproximam e distinguem a perspectiva da economia do acesso da economia do compartilhamento.

Seguindo essa trilha, o ensaio abordou alguns dos conceitos centrais que definem cada uma das duas perspectivas. Ao passo que a economia do acesso se aproxima ontologicamente da filosofia utilitarista, embasada sobre o individualismo, autointeresse e a autopreservação, verificamos que a economia do compartilhamento teria uma aproximação mais íntima da perspectiva antiutilitária, uma abordagem mais aberta, menos estruturada e fundada na pluralidade das possibilidades das relações sociais (inclusive econômicas). Essa dicotomia serviu de base para a construção da árvore de tipificações apresentada neste estudo. Ambas perspectivas econômicas, no entanto, são unidas por um elemento central que se caracteriza como lastro material e o foco das relações de produção e consumo entre as pessoas: 0 acesso.

É importante ressaltar que a abordagem pós-estruturalista adotada não desconsidera a possibilidade de padrões de comportamento utilitaristas. Busca apenas ampliar essa possibilidade apontando para a contingência e a imprevisibilidade das ações humanas. Pesquisas, inclusive, têm demonstrado que a busca pelo engajamento em plataformas de compartilhamento necessita do suporte de componentes econômico-funcionais para ocorrer, como utilidade, redução de custos, familiaridade etc. (HAMARI; SJÖKLINT; UKKONEN, 2015; MÖHLMANN, 2015; ERTZ; DURIF; ARCAND, 2016a). Contudo, a economia do compartilhamento é maior do que a soma desses fatores. $O$ desenvolvimento das práticas e relações da economia do compartilhamento não se restringem ao acesso, pois também possuem como característica o comportamento pró-social de seus agentes, auxiliando-os na obtenção de objetivos que fogem ao mero espectro individual.

Quanto à suposta proliferação dos modelos de mercado de compartilhamento, algumas ressalvas devem ser feitas. Apesar da amplitude que o conceito possa atingir, nem todas as práticas e plataformas virtuais definidas como promotoras da economia do compartilhamento se caracterizam como tal. A grande maioria, ao contrário, se constitui como exemplos de modelos da economia do acesso. Outra ressalva diz respeito à falsa impressão de que qualquer modelo de compartilhamento produz resultados sempre beneméritos. 0 caso do compartilhamento de conteúdo virtual privado, como softwares, músicas, filmes e até mesmo material relacionado a pedofilia e crimes virtuais, são ações deletérias à sociedade e precisam ser combatidas. Schor et al (2015) também destacam que a discriminação e a segregação social são práticas bastante comuns em plataformas colaborativas.

Por outro lado, quando estimulada dentro dos moldes apresentados pelos protótipos tanto dos modelos híbridos quanto dos modelos colaborativos da economia do compartilhamento, a prática de produção ou consumo trará importantes contribuições sociais. Pesquisas têm relacionado a economia do compartilhamento a práticas como a produção e o consumo conscientes e sustentáveis (HAMARI; SJÖKLINT; UKKONEN, 2015; MÖHLMANN, 2015; 
BÖCKER; MEELEN, 2016), à colaboração (BELK, 2010; 2014b) e ao comportamento de anticonsumo (OZANNE; BALLANTINE, 2010).

Por fim, devido ao seu caráter propedêutico, o estudo também suscita a produção de investigações futuras e estimula o desenvolvimento de uma agenda de pesquisas no Brasil. A tipologia apresentada deixa margem para discussões que englobam tanto a área acadêmica quanto empresarial e de políticas públicas. Suscita, por exemplo, a possibilidade de se debater a posição de programas e políticas públicas, e.g., Crediamigo e bolsa família; esforços científicos, e.g., desenvolvimento de trabalhos interdisciplinares; fusões entre empresas, e.g., joint-ventures; associações de empreendimentos de múltiplos setores, e.g., arranjos produtivos locais, feiras-livres, dentre outros.

Similarmente, os achados encontrados no estudo também apontam a outros direcionamentos de pesquisa. A originalidade dos modelos econômicos apresentados, bem como a amplitude e capilaridade mercadológica alcançada por eles, levantam novos questionamentos acerca da formação e organização das relações de mercado. Entender como eles se originam, quais os elementos que contribuem para a sua formação, como operam em meio a diferentes estratégias de mercado e como se dá a coexistência com outros modelos econômicos são pautas de pesquisa que podem ajudar a entender melhor a dinâmica dos mercados atuais. A literatura de construção de mercados, cujas contribuições seminais são atribuídas a Callon (1998), pode trazer importantes contribuições na investigação dessas questões.

Do mesmo modo, entender como os arranjos de práticas mercadológicas e não-mercadológicas (cf. ARAUJO; KJELLBERG; SPENCER, 2008) se organizam para a formação das malhas de práticas da economia do acesso e do compartilhamento traria contribuições importantes para o entendimento da evolução dessas perspectivas. Em ambas as economias, fatores mercadológicos, tecnológicos e sociais se coadunam em uma perspectiva sociotécnica maior (SUTHERLAND; JARRAHI, 2018), capaz de rearranjar as ações dos seus agentes e produzir práticas de mercado diferenciadas.

\section{REFERÊNCIAS}

AKBAR, P.; MAI, R.; HOFFMANN, S. When do materialistic consumers join commercial sharing systems. Journal of Business Research, v. 69, n. 10, p. 4215-4224, 2016.

ARAUJO, L.; KJELLBERG, H.; SPENCER, R. Market practices and forms: introduction to the special issue. Marketing Theory, v. 8, n. 1, p. 5-14, 2008.

BAGOZZI, R. P. Marketing as exchange. The Journal of Marketing, v. 39, p. 32-39, 1975.

BARDHI, F.; ECKHARDT, G. M. Access-based consumption: The case of car sharing. Journal of Consumer Research, v. 39, n. 4, p.881-898, 2012.

BAUDRILLARD, J. A sociedade de consumo. Lisboa: Edições 70, 2011.

BELK, R. Sharing versus pseudo-sharing in Web 2.0. Anthropologist, v. 18, n. 1, p. 7-23, 2014a. 
BELK, R. You are what you can access: Sharing and collaborative consumption online. Journal of Business Research, v. 67, n. 8, p. 1595-1600, 2014b.

. Extended self in a digital world. Journal of Consumer Research, v. 40, n. 3, p. 477500, 2013.

. Sharing. Journal of Consumer research, v. 36, n. 5, p. 715-734, 2010.

. Possessions and the extended self. Journal of Consumer research, v. 15, n. 2, p. 139-168, 1988.

BENTHAM, J. An Introduction of the Principles of Morals and Legislation. Oxford: Clarendon Press, 1996.

BÖCKER, L.; MEELEN, A. A. H. Sharing for people, planet or profit? Analysing motivations for intended sharing economy participation. Environmental Innovation and Societal Transitions, v. 23, 2016. http://dx.doi.org/10.1016/j.eist.2016.09.004.

BOTSMAN, R.; ROGERS, R. What's Mine Is Yours: How Collaborative Consumption Is Changing the Way We Live. London: Collins, 2011.

BOURDIEU, P. Distinction: A social critique of the judgement of taste. Harvard University Press, 1984.

CAILLÉ, A. O princípio de razão, o utilitarismo e o antiutilitarismo. Sociedade e Estado, v. 16, n. 1-2, p. 26-56, 2001.

CALLON, M. The laws of the Markets. Blackwell: Oxford \& Malden, 1998.

CHERRY, C. E.; PIDGEON, N. P. Is sharing the solution? Exploring public acceptability of the sharing economy. Journal of Cleaner Production, v. 195, p. 939-948, 2018.

CHRISTENSEN, C. M. et al. What is disruptive innovation? Harvard Business Review, v. 15, n. 12, p. 1-11, 2015.

COCKAYNE, D. G. Sharing and neoliberal discourse: The economic function of sharing in the digital on-demand economy. Geoforum, v. 31, n. 77, p. 73-82, 2016.

EARL, P. E. Economics and psychology: a survey. The Economic Journal, v. 100, n. 402, p. 718-755, 1990.

ECKHARDT, G. M.; BARDHI, F. The sharing economy isn't about sharing at all. Harvard Business Review, v. 28, 2015.

ECKHARDT, G. M.; BARDHI, F. The Relationship between Access Practices and Economic Systems. Journal of the Association for Consumer Research, v. 1, n. 2, p. 210-225, 2016.

ERTZ, M.; DURIF, F.; ARCAND, M. Business in the hands of consumers: A scale for measuring online resale motivations. Expert Journal of Marketing, v. 4, n. 2, p. 60-76, $2016 \mathrm{a}$.

. Collaborative Consumption: Conceptual Snapshot at a Buzzword. Journal of Entrepreneurship Education, v. 19, n. 2, p. 1-23, 2016b.

. An analysis of the origins of collaborative consumption and its implications for mar-

keting. Academy of Marketing Studies Journal, v. 21, n. 1, p. 1-17, 2017. 
FELSON, M.; SPAETH, J. L. Community structure and collaborative consumption: "A Routine Activity Approach". The American Behavioral Scientist, v. 21, n. 4, p. 614-624, 1978. FISKE, A. P. The four elementary forms of sociality: framework for a unified theory of social relations. Psychological Review, v. 99, n. 4, p. 689, 1992.

FOLKES, V. S. Is Consumer Behavior Different? Advances in Consumer Research, v. 29, 2002.

HAMARI, J.; SJÖKLINT, M.; UKKONEN, A. The sharing economy: Why people participate in collaborative consumption. Journal of the Association for Information Science and Technology. v. 67, 2015, p. 2047-2059. DOI: 10.1002/asi.23552.

HEINRICHS, H. Sharing economy: a potential new pathway to sustainability. Gaia, v. 22, n. 4, p. 228, 2013.

HOBBES, T. Leviatã: ou matéria, forma e poder de um estado eclesiástico e civil. São Paulo: Martin Claret, 1999.

HOUSTON, F. S.; GASSENHEIMER, J. B. Marketing and exchange. The Journal of Marketing, v. 51, p. 3-18, 1987.

JAEGGI, A. V.; GURVEN, M. Natural co-operators: food sharing in humans and other primates. Evolutionary Anthropology: Issues, News, and Reviews, v. 22, n. 4, p. 186-195, 2013.

JOHN, N. A. The social logics of sharing. The Communication Review, v. 16, n. 3, p. 113$131,2013$.

KAPLAN, $\mathrm{H}$. et al. The natural history of human food sharing and cooperation: a review and a new multi-individual approach to the negotiation of norms. Albuquerque, NM: University of Mexico, 2001.

KATSEV, R. Car Sharing: A New Approach to Urban Transportation Problems. Analyses of Social Issues and Public Policy, v. 3 n. 1, p. 65-86, 2003.

KAUL, I.; MENDOZA, R. U. Advancing the concept of public goods. In: KAUL, I. et al. Providing global public goods: Managing globalization, p. 95-111, 2003.

LAPOWSKY, I. Couchsurfing Dilemma: Going for Profit. Inc. Magazine. 2012. Disponível em: http://www.inc.com/magazine/201206/issie-Lapowsky/couchrurfingnew-profit-model. html. Acesso em: 10 ago. 2017.

MARIE, A. Relações de parentesco e relações de produção nas sociedades de linhagem. In: POUILLON, F. A Antropologia Econômica: Correntes e Problemas. Lisboa: Edições 70, 1978. p. 151-202.

MAUSS, M. Sociologia e Antropologia. São Paulo: Cosac Naif, 2003.

MEAD, M. Cooperation and competition among primitive peoples. New Jersey, EUA: Transaction Publishers, 2002.

MILL, J. S. Utilitarismo. Lisboa, PT: Porto Editora, 2005. 
MÖHLMANN, M. Collaborative consumption: determinants of satisfaction and the likelihood of using a sharing economy option again. Journal of Consumer Behaviour, v. 14, n. 3, p. 193-207, 2015.

MOLZ, J. G. Social networking technologies and the moral economy of alternative tourism: The case of couchsurfing.org. Annals of tourism research, v. 43, p. 210-230, 2013.

MORLIGHEM, A. Économie Collaborative: le nouvel art des co. Paris, FR: Décisions durables, 2014.

O'BOYLE, E. J. Requiem for homo economicus. Journal of Markets and Morality, v. 10, n. 2, 2007.

OZANNE, L. K.; BALLANTINE, P. W. Sharing as a form of anti-consumption? An examination of toy library users. Journal of Consumer Behaviour, v. 9, n. 6, p. 485-498, 2010.

PERREN, R.; GRAUERHOLZ, L. Collaborative Consumption. International Encyclopedia of the Social \& Behavioral Sciences, p. 139-144, 2015. https://doi.org/10.1016/B978-0-08097086-8.64143-0.

PLEWNIA, F.; GUENTHER, E. Mapping the sharing economy for sustainability research. Management Decision, v. 56, n. 3, p. 570-583, 2018.

POLANYI, K. A Grande Transformação: as Origens da Nossa Época. 2. ed. Rio de Janeiro: Elsevier, 2012.

RICARDO, D. On The Principles of Political Economy and Taxation. Ontario, CA: Batoche Books, 2001.

RIVERA, J. et al. A netnographic study of P2P collaborative consumption platforms' user interface and design. Environmental Innovation and Societal Transitions, v. 23, p. 11-27, 2017.

SCARABOTO, D. Selling, sharing, and everything in between: The hybrid economies of collaborative networks. Journal of Consumer Research, v. 42, n. 1, p. 152-176, 2015.

SCHOR, J. B. et al. Paradoxes of openness and distinction in the sharing economy. Poetics, v. 54, p. 66-81, 2016.

SILVA, J.T.; RAMALHO, F.R.X.; RIGO, A S. Approaching plural economy concepts and sharing economy experiences. In: EMES - POLANYI INTERNATIONAL SEMINAR. 2., 2016, Paris. Anais ..., Paris, 2016.

SIMMEL, G. As grandes cidades e a vida do espírito (1903). Mana, v. 11, n. 2, p. 577-591, 2005.

SMITH, A. A riqueza das nações: investigação sobre a natureza e suas causas. v I. São Paulo, SP: Editora Nova Cultural, 1996.

SUTHERLAND, W.; JARRAHI, M. H. The sharing economy and digital platforms: A review and research agenda. International Journal of Information Management, v. 43, p. 328341, 2018.

TSOUKAS, H.; CHIA, R. On organizational becoming: Rethinking organizational change. Organization Science, v. 13 n. 5, p. 567-82, 2002. 
WAVE. Cartographie de l'Ingeniosité Collective. 2014. Disponível em: http://www.wave-innovation.com/l-expo.html. Acesso em: 01 de jul. 2017.

WHITEHEAD, A. N. Science and the modern world. London: Free Association Books, 1985.

WIDLOCK, T. Sharing by Default: Outline of an Anthropology of Virtue. Anthropological Theory, v. 4, n. 1, p. 53-70, 2004.

Data de Submissão: 11/12/2018.

Data de Aprovação: 17/06/2019. 